\title{
Opioid-induced respiratory depression in the acute care setting: a compendium of case reports
}

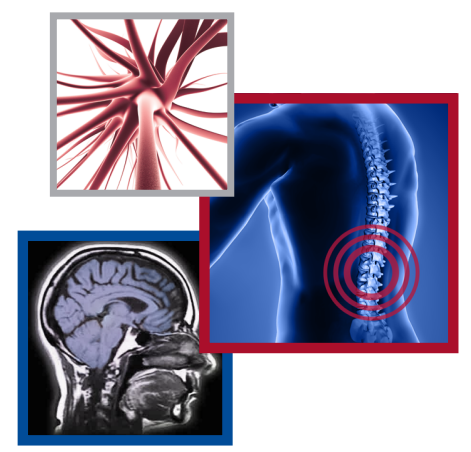

Frank Overdyk ${ }^{1}$, Albert Dahan*,2, Margot Roozekrans², Rutger van der

Schrier ${ }^{2}$, Leon Aarts ${ }^{2} \&$ Marieke Niesters ${ }^{2}$

Practice points

- Opioid-induced respiratory depression (OIRD) is a potentially fatal complication of opioid use both in clinical (perioperative and acute/chronic pain relief) and nonclinical settings (misuse/abuse).

- Since 1980, 105 case reports on critical OIRD in the acute care setting were published in the literature as retrieved from PubMed.

- The majority of patients had no underlying comorbidities that placed them at increased risk for OIRD. Only $30-40 \%$ of cases had a comorbidity possibly related to the OIRD including sleep-disordered breathing, renal impairment, obesity and pulmonary disease, neurological disorders and polymorphisms of the CYP450 enzyme system.

- Most frequently reported opioid related to respiratory depression was morphine, followed by sufentanil and fentanyl. Neuraxial administration was the most frequent route associated with OIRD followed by intravenous dosing.

- In case reports since 2000 , complications in women were disproportionately more common, consistent with their higher opioid sensitivity. Advanced age was not a factor related to OIRD.

- This analysis of case reports indicates that OIRD is a significant cause of preventable morbidity and mortality and that OIRD is difficult to predict. Dose titration to effect alongside comprehensive and frequent respiratory and level of consciousness monitoring remains the most important safeguard against preventable harm to undetected OIRD.

SUMMARY Opioid-induced respiratory depression (OIRD) is a potentially fatal complication of treatment with opioids. Little is known about patient- and case-related factors associated with OIRD. One-hundred-and-five available case reports on OIRD in 134 patients (12 years and older) in the perioperative, obstetric or emergency care setting, published since 1980, were retrieved from the literature. The most frequently reported case-related factors were: morphine use, perioperative setting and obstetrics, neuraxial or intravenous administration. The most frequently reported patient-related factors involved were: female gender, sleep-disordered breathing, obesity, renal impairment, pulmonary disease and CYP450 enzyme polymorphisms. While the analysis has limitations, it confirms that OIRD in the acute setting involves complex and interrelated factors and is a significant cause of preventable morbidity and mortality.

'Department of Anesthesiology, Hofstra North Shore-LIJ School of Medicine, Hempstead, New York, NY, USA

2Department of Anesthesiology, Leiden University Medical Center, Leiden, The Netherlands

*Author for correspondence: Tel.: +31 71526 2301; Fax: +31 71526 6230; ea.dahan@lumc.nl

\section{KEYWORDS}

- analgesia - case report

- case series - mortality

- opioid-induced respiratory depression • opioids

- perioperative complications • respiratory depression

Future $\because$ Medicine ${ }_{\text {part of }}$ 
Opioid-induced respiratory depression (OIRD) is a potentially fatal complication of opioid use in both acute and chronic pain therapy, and nonclinical settings, such as opioid misuse and addiction [1]. Although fatalities from OIRD in the clinical setting are well described in case reports, there is no compendium of patient and nonpatient-related factors that are common to these serious adverse events. We have previously published an analysis of case reports of OIRD in pediatric patients ( $0-12$ years of age) and patients treated with opioids for chronic pain $[2,3]$. In the current study, we apply our methodology from earlier publications to the cohort of case reports describing OIRD in adolescent and adult patients with OIRD in acute care settings. Our prior analysis of OIRD case reports in pediatric patients revealed that fatal OIRD was associated with children receiving codeine following tonsillectomy or adenoidectomy. Our publication coincided with a US FDA black box warning of codeine use in these procedures, prompted in part by ten deaths and three reported overdoses associated with codeine in the period 1969-2012 [4]. This association strengthened our suspicion that a careful analysis of case reports may reveal specific demographic, pharmacological or clinical covariates that confer additional risk for OIRD. We describe our findings for patients receiving opioids for acute pain, including obstetrical pain, and patients prescribed opiate-containing formulations for cough and dyspnea.

\section{Methods}

We retrieved case reports and case series on OIRD from the PubMed database written in English, Dutch or French during the period 1980-2013 [5]. Included were cases of patients 12 years or older who developed OIRD in response to opioids during treatment of pain in the perioperative setting or emergency department, labor pain, cough/dyspnea or procedural sedation. Cases related to human errors involving errors in prescribing or in the programming of infusion devices were excluded.

OIRD was defined as a clinical assessment of impaired spontaneous ventilation requiring one of the following interventions: Mask ventilation; effective reversal of OIRD with naloxone and/ or doxapram; endo-tracheal intubation; positive pressure ventilation followed by unplanned admission to an intensive care or monitored setting.
Causality between opioid treatment and OIRD was established by authors $\mathrm{AD}$ and $\mathrm{MN}$, and differences in opinion were resolved by consensus. A priori, the cases were divided into those published between 1980 and 1999, and those between 2000 and 2013, since this chronological partition was meaningful in our study of OIRD in chronic pain, as well as divided into three age groups, namely $12-30,31-60$ and 61 years of age or older. The following variables were retrieved from each case:gender, age, comorbidities, opioid, route of administration, clinical setting and outcome.

Results

- Literature

The PubMed search resulted in 4798 publications of which 4693 did not meet inclusion criteria or cited adverse events not deemed causally related to opioids by the authors. In total, 105 case reports were included in our analysis: 70 reports involving 97 patients during 1980-1999 [6-75], and 35 involving 37 patients during 2000-2013 [76-110]. The number of reports per year decreased from 4.9 cases per year in $1980-1999$ to 2.9 cases per year in 2000-2013.

\section{- Patient characteristics}

Patient age was not significantly different before or after 2000 (Table 1). Men and women were equally represented prior to 2000 but women outnumbered men 2:1 after 2000 . The majority of patients had no underlying medical or neurological disease that predisposed them to OIRD. Only 31\% of patients prior to 2000 and 43\% of patients since the year 2000 had comorbidity possibly related to the OIRD. These predispositions included sleep-disordered breathing (SDB), renal impairment, obesity $(\mathrm{BMI}>30)$ and pulmonary disease prior to 2000 , whereas since 2000 comorbidities predisposing to OIRD included renal impairment, pulmonary disease, neurological disorders and polymorphisms of the CYP450 enzyme system (Table 1). The latter occurred especially in cases in which metabolites produce active compounds (such as in the case of tramadol and codeine).

\section{- Case-related specifics}

Morphine was the preeminent opioid used in both pre- and post-2000 periods $(>30 \%)$ whereas sufentanil and fentanyl were the next most common in the pre- and post-2000 time periods (Table 2). Alfentanil was only 
Table 1. Characteristics of all 134 patients described in 105 case reports on critical opioid-induced respiratory depression in the acute care setting.

\begin{tabular}{|c|c|c|}
\hline \multirow[t]{2}{*}{ Patient characteristics } & \multicolumn{2}{|c|}{ Period (year) } \\
\hline & 1980-1999 & $2000-2013$ \\
\hline Number of cases & 97 & 37 \\
\hline \multicolumn{3}{|l|}{ Gender: } \\
\hline - Men, n (\%) & $46(47)$ & $14(38)$ \\
\hline - Women, n (\%) & $50(52)$ & $21(58)$ \\
\hline - Unknown, n & 1 & 2 \\
\hline \multicolumn{3}{|l|}{ Age: } \\
\hline - Median (range), years & $51.5(16-85)$ & $44.0(14-81)$ \\
\hline - Cohort $12-30$ years, $\mathrm{n}(\%)$ & $23(24)$ & $14(38)$ \\
\hline - Cohort 31-60 years, n (\%) & $36(37)$ & $9(24)$ \\
\hline - Cohort 61 years and older, n (\%) & $37(38)$ & $12(32)$ \\
\hline \multicolumn{3}{|l|}{ Underlying disease: } \\
\hline - Sleep-disordered breathing, n (\%) & $16(17)$ & $1(3)$ \\
\hline - Renal impairment, n (\%) & $9(9)$ & $3(8)$ \\
\hline - Obesity, n (\%) & $4(3)$ & $2(6)$ \\
\hline - Pulmonary disease, $\mathrm{n}(\%)$ & $2(2)$ & $1(3)$ \\
\hline - Neurological disorders, n (\%) ${ }^{\dagger}$ & - & $5(14)$ \\
\hline - CYP450 polymorphisms, n (\%) & - & $5(14)$ \\
\hline
\end{tabular}

incriminated in OIRD prior to the year 2000. Conversely, remifentanil was incriminated in six cases, three of which involved Patient-controlled analgesia (PCA) for labor pain, all since the year 2000. Tramadol was reported as cause of OIRD in seven cases (six after 2000). The setting in which OIRD was most frequently reported was perioperative (with 86 and $69 \%$ of cases in preand post-2000 periods, respectively), followed by the obstetrical ward. In both periods, neuraxial was the most common route of administration followed by the intravenous route, both nurse administered and PCA.

\section{- Outcomes}

Serious adverse events resulting in hypoxic brain damage or death were reported in six $(9 \%)$ patients and two $(6 \%)$ patients in pre- and post-2000 cases, respectively.

\section{Discussion}

- Opioid-induced respiratory depression

In this study, we included reports on 134 patients that developed OIRD in an acute setting. Opioids have a direct depressant effect on neurons that express the MOP ( $\mu$-opioid peptide) receptor in the respiratory centers of the brainstem [111]. Respiratory depression is life threatening when depression of respiratory neurons exceeds the respiratory stimulatory effects of retained $\mathrm{CO}_{2}$ or other stimulants, such as pain, heightened arousal and visual cues. At low opioid dosagesor slow infusion rates, the patient will continue breathing but arterial $\mathrm{P}_{2} \mathrm{CO}_{2}\left(\mathrm{PaCO}_{2}\right)$ will increase (hypercapnia). The accumulating $\mathrm{P}_{2} \mathrm{CO}_{2}$ stimulates breathing via activation of central and peripheral chemoreceptors. When an opioid dose becomes a threat to the patient's safety, breathing activity will decrease further and become irregular and apneic even at high arterial $\mathrm{P}_{\mathrm{a}} \mathrm{CO}_{2}$ [112]. While physicians may have some sense of 'standard' dosing regimens, opioid sensitivity is highly variable among patients (dose may vary by a factor of 40), and care is always required when dosing a patient in any acute setting. In one of the retrieved case reports, Lötsch et al. describe a young female that received morphine for postoperative pain relief. Due to the slow onset times of morphine (related to the lag time needed to cross the blood-brain barrier), the patient's pain was not alleviated immediately and further infusions of morphine were given eventually leading to a fatal cardiac arrest [93]. This was a classic example of the greater potency but slower time to onset of opioid analgesia in women compared with men as described by Sarton et al. [113], a pharmacokinetic/pharmacodynamic nuance, unbeknown to most physicians. In most cases reports, OIRD developed without any indication of an obvious overdose, suggesting that OIRD may 


\begin{tabular}{|c|c|c|}
\hline \multirow[t]{2}{*}{ Case characteristics } & \multicolumn{2}{|c|}{ Period (year) } \\
\hline & 1980-1999 & $2000-2013$ \\
\hline Number of cases & 97 & 37 \\
\hline \multicolumn{3}{|l|}{ Drugs involved: } \\
\hline - Morphine, n (\%) & $32(33)$ & $15(41)$ \\
\hline - Sufentanil, n (\%) & $26(27)$ & $3(8)$ \\
\hline - Fentanyl, n (\%) & $15(15)$ & $7(19)$ \\
\hline - Alfentanil, n (\%) & $12(11)$ & - \\
\hline - Remifentanil, n (\%) & - & $6(16)$ \\
\hline - Codeine, n (\%) & $2(2)$ & $3(8)$ \\
\hline - Tramadol, n (\%) & $1(1)$ & $6(16)$ \\
\hline \multicolumn{3}{|l|}{ Setting: } \\
\hline - Perioperative (nonobstetric), n (\%) & $84(86)$ & $26(70)$ \\
\hline - Obstetrics, n (\%) & $10(11)$ & $6(16)$ \\
\hline - Acute pain, n (\%) & $2(2)$ & $3(8)$ \\
\hline - Sedation, n (\%) & $1(1)$ & - \\
\hline - Cough/dyspnea, n (\%) & - & $1(3)$ \\
\hline \multicolumn{3}{|l|}{ Administration route: } \\
\hline - Neuraxial, n (\%) & $43(44)$ & $12(32)$ \\
\hline - Intravenous, n (\%) ${ }^{\dagger}$ & $37(38)$ & $15(41)$ \\
\hline - Intravenous PCA, n (\%) & $12(12)$ & $5(14)$ \\
\hline - Other, $\mathrm{n}(\%)^{\ddagger}$ & $3(3)$ & $3(8)$ \\
\hline
\end{tabular}

have been precipitated by other factors, such as underlying disease, an inherent (genetic) or acquired increased sensitivity to opioids (an acquired increase in opioid sensitivity has been observed after repetitive hypoxic events in children) [114], pharmacokinetic and pharmacodynamics drug interactions (e.g., the combination of opioids and sedatives may enhance the probability of respiratory depression) and genetic polymorphisms of genes involved in drug metabolism $[2,3]$. Our analysis indicates that opioid sensitivity and OIRD is difficult to predict in individual patients. We therefore advise careful titration of the opioid to effect, with meticulous and preferably continuous monitoring of respiratory variables and level of consciousness. Furthermore, independent of the level of monitoring, it is equally important to take into account the known pharmacokinetics and dynamics of the opioid as well as all patient factors that may enhance the opioid's effects on breathing.

\section{- Comparison with case reports on OIRD in pediatrics \& chronic pain}

In two previous reports, we presented an analysis of case reports in pediatric and chronic pain patients published since 1980 [2,3]. In our review of pediatric case reports, we retrieved 27 cases in patients 12 years of age or younger [2]. In eight cases, OIRD was due to aninadvertent overdose, seven of which were fatal. In the remaining 19 patients, the most notable patterns were:

- Morphine administration in patients with renal failure causing the accumulation of active metabolites;

- Morphine intoxication following codeine administration in eight patients with CYP2D6 gene polymorphisms associated with the ultrarapid metabolizer phenotype;

- OIRD in patients following adenotonsillectomy for recurrent tonsillitis and/or obstructive sleep apnea.

In 42 cases of OIRD in chronic pain patients [3], cases published before the year 2000 predominantly involved morphine in oncology patients whereas cases published since 2000 predominantly involved methadone, transdermal fentanyl and oxycodone in patients with chronic noncancer pain, most importantly musculoskeletal pain. Patient-related factors included renal failure and drug interactions on the CYP450 system. 


\section{- Case-related factors}

In our current analysis, the following case-related factors were apparent:

- Morphine was the drug reported most frequently followed by the phenylpiperidines fentanyl and sufentanil, reflecting their frequency of use in the perioperative setting. The replacement of alfentanil by remifentanil apparent in pre-2000 to post-2000 cases reflects the change in popularity and availability of these agents in local practice;

- Perioperative (postanesthesia care unit and ward) and obstetrics accounted for greater than $85 \%$ of the locations of OIRD. The appearance of remifentanil-induced OIRD after 2000 in obstetric wards reflects a clinical trend in which remifentanil PCA replaces local anestheticbased epidural analgesia for the treatment of labor pain $[107,108,110]$. Focus on the respiratory effects of remifentanil PCA for labor pain is required as it is our belief that this form of analgesia will increase significantly in the upcoming years;

- Neuraxial opioid administration and single intravenous administrations accounted for more than $70 \%$ of the cases.

\section{- Patient-related factors}

In our current analysis, the following patient-related factors were apparent:

- A greater number of women experienced OIRD in cases since 2000. As suggested by a recent meta-analysis, women have a greater opioid sensitivity compared with men [115]. This regards to both analgesia and respiratory depression [116]. The meta-analysis showed that greater opioid sensitivity in females became apparent during prolonged opioid treatment periods ( $>24 \mathrm{~h})$;

- The age range of OIRD was $14-85$ years and not different in pre- and post-2000 periods. Our analysis revealed that advanced age was not a risk factor for OIRD (see below);

- Comorbidities played a causal role in the development of OIRD in 31\% (pre-2000) and 41\% (post-2000) of cases. Most prevalent were SDB (17 cases) and renal impairment (nine cases). Renal impairment will cause the accumulation of toxic metabolites (e.g., the accumulation of morphine-6-glucuronide following morphine treatment) and requires providers to prescribe opioids and their active metabolites that are cleared through nonrenal pathways. In children, SDB has been associated with an increased analgesic sensitivity to opioids [114]. Rodents exposed to recurrent hypoxic episodes show a greater respiratory sensitivity to opioids [117]. These are important observations and suggest a link between recurrent hypoxic events and OIRD, possibly also in the adult population;

- Seven cases of tramadol-induced respiratory depression are reported [65,89,97,103-105], most of which are related to gene duplication of the CYP2D6 system (i.e., rapid and ultra-rapid metabolizers) causing an excess of the active metabolite $O$-desmethyl tramadol inducing respiratory depression, even when just a low dose was administered. $O$-desmethyl tramadol has a much greater affinity for the $\mu$-opioid receptor than the parent drug.

In an approach similar to ours, Lee and Domino recently published a list of factors associated with OIRD from the ASA Closed Claims Project Database (CCDB) related to malpractice lawsuits during treatment of acute pain from 1990 to 2009 [118]. Although the inclusion criteria for our data sets differ (published case reports vs cases related to claims; global reports vs US-based cases) there is agreement among risk factors associated with OIRD. In 86 cases, respiratory depression associated factors included neuraxial pain therapy, evidence of sleep apnea and co-medication (i.e., multimodal pain therapy and addition of nonopioid sedatives). In contrast to our findings, PCA played an appreciable role as cause of OIRD especially when combined with other (non-neuraxial) modes of pain therapy. In a third of cases, involvement of more than one physician in prescribing opioids was associated with respiratory depression. As often described, poor communication between prescribing physicians and nursesis mentioned as contributing to unrecognized and serious respiratory depression. Finally, in common with our findings, advanced age was not a factor associated with respiratory depression. This may be related to the higher acceptance of a fatal outcome from pain therapy in elderly (and possibly sicker) patients compared with younger patients.

\section{Prevalance of OIRD}

Our analysis of case reports gives us a reliable assessment of both case- and patient-related 
factors of OIRD. However, our analysis does not provide an insight in the number of patients (i.e., prevalence) experiencing fatal or nonfatal OIRD. The number of patients described $(\mathrm{n}=$ 135 ) is just a small fraction of the total number of patients that we know to experience OIRD. Also US data from malpractice claims provide little information in this respect. For example, Lee and Domino describe only 86 cases (period 1990-2006) in adult perioperative patients, while Subramanyam et al. [119] describe 16 and six pediatric patients following tonsillectomy that had opioid-related fatal and nonfatal respiratory depression, respectively. A recent publication states that from 1999 to 2010, the number of yearly deaths due to opioid overdose has increased from 1.4 to 5.3 per 100,000 (US population) or approximately 16,000 individuals in 2010 [120]. The increase over time paralleled the sale of opioids and admissions for opioid abuse treatment. Evidently, this number includes opioid abuse/ misuse outside the medical setting, opioid treatment for chronic and acute pain and palliative case, but indicates the enormity of the problem. We estimate that nonfatal occurrences of OIRD must be a factor of at least 100 greater.

\section{Conclusion}

In aggregate, the $\mathrm{CCDB}$ data, this analysis of case reports in the acute setting, and our previous analyses in chronic pain patients and pediatrics, support the theory that OIRD is a significant cause of preventable morbidity and mortality. Despite the presence of associated factors, our analyses indicate that OIRD is difficult to predict in any one patient and we therefore recommend that as a first step in the prevention of OIRD, to carefully titrate the patient to effect. Moreover, all patients that receive an opioid in the acute setting must be adequately observed and continually electronically monitored. Other measures that may prevent OIRD include adequate education of all involved in the deliverance of pain therapy and optimizing communication between caregivers (nurses and doctors). We are aware that these recommendations are challenging and costly, but not as costly as the inadvertent loss of life from well-intended but lethal opioid therapy.

Evidently, our analysis prompts further research in the analysis of currently available large data sets on OIRD, such as may be available from hospital data management systems or insurance companies. This will result in specific factors that may be associated or predictive of OIRD. Additionally, we would like to encourage physicians to perform prospective studies on OIRD, for example, in the acute hospital setting (recovery room/PACU) and also in the wards where opioids are often administered without proper monitoring. Studies as suggested here will bring us forward in the continuous struggle to make opioid therapy safer.

\section{Future perspective}

We are looking forward to the development of specific nonopioid drugs that prevent respiratory depression during opioid therapy. Several types of drugs are being developed including ampakines and BK-channel blockers. These agents stimulate breathing through activation of respiratory centers at central (i.e., within the $\mathrm{CNS}$ ) or peripheral (i.e., at the carotid bodies) sites, independent of any action at the opioid receptors, and consequently offset the reduced breathing from opioids without affecting analgesia. Possibly combining these drugs with common opioids will reduce the probability of opioid-related morbidity and mortality. Still vigilance remains required and development of sophisticated monitoring tools in patients taking potent opioids and patients with comorbidity prone to develop respiratory depression is additionally required. We envision the development of telemetric monitors of the cardiorespiratory system attached to smart sensors embedded in watches, smartphones or garments. Yet again, these approaches may not result in the (false) feeling of safety, as opioids remain potentially fatal under all conditions.

\section{Financial \& competing interests disclosure}

Since 2010, the Leiden University Medical Center, Anesthesia \& Pain Research Unit has performed studies on opioidinduced respiratory depression sponsored by Mundipharma Research Ltd (Cambridge, UK) and on reversal of opioidinduced respiratory depression sponsored by Galleon Pharmaceuticals, Inc. (Horsham, PA, USA) and Revive Therapeutics Ltd (Vaughan, ON, Canada). The authors have no other relevant affliations or financial involvement with any organization or entity with a financial interest in or financial conflict with the subject matter or materials discussed in the manuscript apart from those disclosed.

No writing assistance was utilized in the production of this manuscript. 


\section{References}

Papers of special note have been highlighted as: - of interest; $\bullet$ of considerable interest

1 Dahan A, Aarts L, Smith TW. Incidence, reversal and prevention of opioid-induced respiratory depression. Anesthesiology 112, 226-238 (2010).

- Recent comprehensive review on mechanisms of opioid-induced respiratory depression. Pharmacological preventive options are discussed.

2 Niesters M, Overdyk F, Smith T, Aarts L, Dahan A. Opioid-induced respiratory depression in paediatrics. A review of case reports. Br. J. Anaesth. 110, 175-182 (2013).

- First systematic review on opioid-induced respiratory depression in neonates and children.

3 Dahan A, Overdyk F, Smith T, Aarts L, Niesters M. Pharmacovigilance. A review of opioid-induced respiratory depression in chronic pain patients. Pain Physician 16, E85-E94 (2013).

4 US Department of Health and Human Services. FDA drug safety communication: safety review update of codeine use in children. New boxed warning and contraindication on use after tonsillectomy and/or adenoidectomy. www.fda.gov/Drugs/DrugSafety/ucm339112. htm

5 NCBI.

www.ncbi.nlm.nih.gov

6 Christensen V. Respiratory depression after extradural morphine. Br. J. Anaesth. 52, 841 (1980).

7 McDonald AMM. Complication of epidural morphine. Anaesth. Int. Care 8, 490-491 (1980).

8 Gustafsson LL, Feychting B, Klingstedt C. Late respiratory depression after concomitant use of morphine epidurally and parenterally. Lancet 8225, 892-893 (1981).

9 Rafferty TD, Ruskis A, Sasaki C, Gee JB. Perioperative considerations in the management of tracheotomy for the obstructive sleep apnoea patient. Br. J. Anaesth. 52, 619-622 (1980).

10 Lee JK, Hanowell S, Kim YD, Macnamara TE. Morphine-induced respiratory depression following bilateral carotid body endarterectomy. Anesth. Analg. 60, 64-65 (1981).

11 Vaughn RL, Bennett CR. Fentanyl chest wall rigidity syndrome - A case report. Anesth. Progr. 28, 50-51 (1981).

12 Welch DB. Epidural narcotics and dural puncture. Lancet 8210, 55 (1981).
13 Nilsson C, Rosberg B. Recurrence of respiratory depression following neurolept analgesia. Acta. Anaesth. Scand. 26, 240-241 (1982).

14 Odoom JA, Sih IL. Respiratory depression after intrathecal morphine. Anesth. Analg. 61, 70 (1982)

15 Barnes JN, Goodwin FJ. Dihydrocodeine narcosis in renal failure. Br. Med. J. 286, 438-439 (1983).

16 Cohen SE, Rothblatt AJ, Albright GA. Early respiratory depression with epidural narcotic and intravenous droperidol. Anesthesiology 59, 559-560 (1983).

17 Brahams D. Death of patient participating in trial of oral morphine for relief of postoperative pain. Lancet 8385, 1083-1084 (1984).

18 Glass PSA. Respiratory depression following only $0.4 \mathrm{mg}$ of intrathecal morphine. Anesthesiology 60, 256-257 (1984).

19 Sebel PS, Lalor JM, Flynn PJ, Simpson BA. Respiratory depression after alfentanil infusion. Br. Med. J. 289, 1581-1582 (1984).

20 Brown DL. Postoperative analgesia following thoracotomy: danger of delayed respiratory depression. Chest 88, 779-780 (1985).

21 Chang J, Fish KJ. Acute respiratory arrest and rigidity after anesthesia with sufentanil: a case report. Anesthesiology 63, 710-711 (1985).

22 Corke CF, Wheatley RG. Respiratory depression complicating epidural diamorphine. Anaesthesia 40, 1203-1205 (1985).

23 Jyu C, Lamb JD. Respiratory depression following epidural morphine. Can. Anaesth. Soc. J. 32, 99-100 (1985).

24 King HK, Tsai SK. Delayed respiratory depression following repeated intrathecal low dose morphine. Anaesth. Int. Care 13, 334-335 (1985).

25 Wiggum DC, Cork RC, Weldon ST, Gandolfi AJ, Perry DS. Postoperative respiratory depression and elevated sufentanil levels in a patient with chronic renal failure. Anesthesiology 63, 708-710 (1985).

26 Knape JTA. Early respiratory depression resistant to naloxone following epidural buprenorphine. Anesthesiology 64, 382-384 (1986).

27 Lamarche Y, Martin R, Reiher J, Blaise G. The sleep apnoea syndrome and epidural morphine. Can. Anaesth. Soc. J. 33, 231-233 (1986).

28 Osborne RJ, Joel SP, Slevin ML. Morphine intoxication in renal failure: the role of morphine-6-glucuronide. Br. Med. J. 292, 1548-1549 (1986).

-• First indication that morphine's active metabolite M6G may be implicated in clinical cases of morphine toxicity.

29 Apfel WC. Possible roles of normeperidine and hyponatremia in a postoperative death. Can. Med. Assoc. J. 137, 912-913 (1987).

30 Blackburn C. Respiratory arrest after epidural sufentanil. Anaesthesia 42, 665-666 (1987).

31 Fuller JD, Crombleholme WR. Respiratory arrest and prolonged respiratory depression after one low, subcutaneous dose of alphaprodine for obstetric analgesia. $J$. Reprod. Med. 32, 149-151 (1987).

32 Keamy MF, Cadieux RJ, Kofke WA, Kales A. The occurrence of obstructive sleep apnea in a recovery room patient. Anesthesiology 66, 232-234 (1987).

33 London SW. Respiratory depression after single epidural injection of local anesthetic and morphine. Anesth. Analg. 66, 797-799 (1987).

34 Smallwood JA, Benjamin S, Brown T, Smart CJ. Opiate analgesic toxicity in patients with renal dysfunction undergoing surgery. $\mathrm{Br}$. J. Urol. 60, 181-182 (1987).

35 Wells DG, Davies G. Profound central nervous system depression from epidural fentanyl for extracorporeal shock wave lithotripsy. Anesthesiology 67, 991-992 (1987).

36 Wüst HJ, Bromage PR. Delayed respiratory arrest after epidural hydromorphone. Anaesthesia 42, 404-406 (1987).

37 Abouleish E. Apnoea associated with the intrathecal administration of morphine in obstetrics: a case report. Br. J. Anaesth. 60, 592-594 (1988).

38 Gabrielczyck MR. Acute airway obstruction after uvulopalatopharyngoplasty for obstructive sleep apnea syndrome. Anesthesiology 69, 941-943 (1988).

39 Mahla ME, White SE, Moneta MD. Delayed respiratory depression after alfentanil. Anesthesiology 69, 593-595 (1988).

40 Patt RB. Delayed postoperative respiratory depression associated with oxymorphone. Anesth. Analg. 67, 403-404 (1988).

41 Robinson D. Respiratory arrest after recovery from anaesthesia supplemented with sufentanil. Can. J. Anaesth. 35, 101-102 (1988).

42 Covington EC, Gonsalves-Ebrahim L, Currie KO, Shepard KV, Pippenger CE. Severe respiratory depression from patient-controlled analgesia in renal failure. Psychosomatics 30 , 226-228 (1989). 
43 Jaffe RS, Coalson D. Recurrent respiratory depression after alfentanil administration. Anesthesiology 70, 151-153 (1989).

44 Overweg-van Kints J, Blackburn CL, Groen HBM, Stricker BHCH. Apnea after epidural sufentanil (in Dutch). Ned. Tijdsch. Geneesk. 133, 988-991 (1989).

45 Steinstra R, van Poorten F. Immediate respiratory arrest after caudal epidural sufentanil. Anesthesiology 71, 993-994 (1989).

46 Tierney NM, Pollard BJ, Doran BRH. Obstructive sleep apnoea. Anaesthesia 44, 235-237 (1989).

47 Bodd E, Jacobsen D, Lund E, Ripe $\AA$, MØrland J, Wiik-Larsen E. Morphine-6glucuronide might modulate the prolonged opioid effect of morphine in acute renal failure. Hum. Exp. Tox. 9, 317-321 (1990).

48 Brockway MS, Noble DW, Sharwood-Smith $\mathrm{GH}, \mathrm{McClure} \mathrm{JH}$. Profound respiratory depression after extradural fentanyl. $\mathrm{Br}$. J. Anaesth. 64, 234-235 (1990).

49 Chisholm RH, Fleischl J. Respiratory arrest with epidural fentanyl. Anaesth. Int. Care 18, 423 (1990).

50 Hudson RJ. Apnoea and unconsciousness after apparent recovery from alfentanilsupplemented anaesthesia. Can. J. Anaesth. 37, 255-257 (1990).

51 Krane BD, Kreutz JM, Johnson DL, Mazuzan JE. Alfentanil and delayed respiratory depression: case studies and review. Anesth. Analg. 70, 557-561 (1990).

52 Palmer CM. Early respiratory depression following intrathecal fentanyl-morphine combination. Anesthesiology 74, 1153-1155 (1991).

53 VanDerCar DH, Martinez AP, De Lisser EA. Sleep apnea syndromes: a potential contraindication for patient-controlled analgesia. Anesthesiology 74, 623-624 (1991).

54 Weightman WM. Respiratory arrest during epidural infusion of bupivacaine and fentanyl. Anesth. Int. Care. 19, 282-284 (1991).

55 Cassinello F, Peral A, Anduenza A, Mourelle I. Respiratory depression after alfentanil. Anaesthesia 47, 718 (1992).

56 Rosaeg OP, Suderman V, Yarnell RW. Early respiratory depression during Caesarian section following epidural meperidine. Can. J. Anaesth. 39, 71-74 (1992).

57 Tixier-Wulff S, Jourdan MC. Respiratory insufficiency following buprenorphine injection (in French). Ann. Fr. Anesth. Réanim. 11, 240-241 (1992).

58 Etches RC. Respiratory depression associated with patient-controlled analgesia: a review of eight cases. Can. J. Anaesth. 41, 125-132 (1994).

59 Hays RL, Palmer CM. Respiratory depression after intrathecal sufentanil during labor. Anesthesiology 81, 511-512 (1994).

60 Baker MN, Sarna MC. Respiratory arrest after second dose of intrathecal sufentanil. Anesthesiology 83, 231-232 (1995).

61 Bennotte MT, Baele P, Aubert G, Rodenstein DO. Nasal continuous positive airway pressure in the perioperative management of patients with obstructive sleep apnea submitted to surgery. Chest 107, 367-374 (1995).

62 Greenhalgh CA. Respiratory arrest in a parturient following intrathecal injection of sufentanil and bupivacaine. Anaesthesia 51, 173-175 (1996).

63 Morley AD. Profound respiratory depression with morphine patient-controlled analgesia in an elderly patient. Anaesth. Int. Care 24, 287 (1996).

64 Quist RJ, Vuyk J, Dahan A. Hypercapnic coma after general anesthesia in a patient with obstructive sleep apnea syndrome (in Dutch). Ned. Tijdschr. Anesthesiol. 9, 39-43 (1996).

65 Barnung SK, Treschow M, Borgbjerg FM. Respiratory depression following oral tramadol in a patient with impaired renal function. Pain 71, 111-112 (1997).

66 Cornish PB. Respiratory arrest after spinal anesthesia with lidocaine and fentanyl. Anesth. Analg. 84, 1387-1388 (1997).

67 Ferouz F, Norris MC, Leighton BL. Risk of respiratory arrest after intrathecal sufentanil. Anesth. Analg. 85, 1088-1090 (1997).

68 Lu JK, Manuillang TR, Staples MH, Kern SE, Bailey PL. Maternal respiratory arrests, sever hypotension, and fetal distress after administration of intrathecal sufentanil and bupivacaine after intravenous fentanyl. Anesthesiology 87, 170-172 (1997).

69 Ostermeier AM, Roizen MF, Hautkappe M, Klock PA, Klafta JM. Three sudden postoperative respiratory arrests associated with epidural opioids in patients with sleep apnea. Anesth. Analg. 85, 452-460 (1997).

70 Fournier R, Gamulin Z, Van Gessel E. Respiratory depression after $5 \mu \mathrm{g}$ intrathecal sufentanil. Anesth. Analg. 87, 1377-1378 (1998).

71 Katsiris S, Williams S, Leighton BL, Halpern S. Respiratory arrest following intrathecal injection of sufentanil and bupivacaine in a parturient. Can. J. Anaesth. 45, 880-883 (1998).
72 Smyth E, Egan TD. Apneic oxygenation associated with patient-controlled analgesia. J. Clin. Anesth. 10, 499-501 (1998).

73 Sternlo JEG, Sandin RH. Recurrent respiratory depression after total intravenous anesthesia with propofol and alfentanil. Anaesthesia 43, 369-381 (1998).

74 Dworzak H, Fuss F, Büttner T. Longterm respiratory depression following intrathecal morphine and simultaneous sedation with midazolam (in German). Anaesthesist 48, 639-641 (1999).

75 Francis PH. Respiratory depression after intra-articular morphine. Anaesth. Int. Care 27, 669-670 (1999).

76 Alsahaf MH, Stockwell M. Respiratory failure due to the combined effects of transdermal fentanyl and epidural bupivacaine/ diamorphine following radical nephrectomy. J. Pain Symptom Manage. 20, 210-213 (2000).

77 Angst MS, Bührer M, Lötsch J. Insidious intoxication after morphine treatment in renal failure: delayed onset of morphine-6glucuronide. Anesthesiology 92, 1473-1476 (2000).

- Illustrative cases on the importance of M6G in morphine toxicity in a patient with renal failure.

78 Krenn H, Jellinek H, Haumer H, Oczenski W, Fitzgerald R. Naloxone-resistant respiratory depression and neurological eye symptoms after intrathecal morphine. Anesth. Analg. 91, 432-433 (2000).

79 Scammel SJ. Apnoea with intrathecal morphine. Anaesth. Int. Care 28, 708 (2000).

80 Gaul C, Winterholler M. Post polio syndrome and weaning failure 40 years after the last polio epidemic (in German). Anaesthesist 51, 378-382 (2002).

81 Kehl F, Erfkamp S, Roewer N. Respiratory arrest during caesarean section after intrathecal administration of sufentanil in combination with $0.1 \%$ bupivacaine $10 \mathrm{ml}$ Anaesth. Int. Care 30, 698-699 (2002).

82 Kuczkowski KM. Respiratory arrest in a parturient following intrathecal administration of fentanyl and bupivacaine as part of a combined spinal-epidural analgesia for labor. Anaesthesia 57, 939-940 (2002).

83 Magi E, Recine C, Klockenbusch B, Cascianini EA. A postoperative respiratory arrest in a post poliomyelitis patients. Anaesthesia 58, 98-99 (2003).

84 Neustein SM, Cottone TM. Prolonged respiratory depression after intrathecal morphine. J. Cardiothor. Vasc. Anesth. 17, 201-203 (2003). 
85 Celik JB, Reisli R, Sarkilar G, Okesli S. Respiratory arrest after intrathecal injection of sufentanil and bupivacaine.; Acta Anaesthesiol. Scand. 48, 793-794 (2004).

86 Gasche Y, Daali Y, Fathi M. Codeine intoxication associated with ultrarapid CYP2D6 metabolism. N. Eng. J. Med. 351, 2827-2831 (2004).

- Illustrative case report linking codeineinduced opioid toxicity to genetic polymorphism of the CYP system. Toxicity in this case was due to an increased metabolism of codeine into morphine.

87 Holmes J, Maye JP. Postoperative respiratory depression and unresponsiveness following epidural opiate administration: a case report. Am. Assoc. Nurse Anesth. J. 72, 126-128 (2004).

88 Ho AMH, Chen S, Karmakar MK. Central apnoea after balanced general anaesthesia that included dexmedetomidine. Br. J. Anaesth. 95, 773-775 (2005).

89 Ouro-Bang'na Maman AF, Ahouangbévi S, Chobli M. Respiratory depression after intrathecal injection of tramadol with hyperbaric bupivacaine. Can. J. Anesth. 53, 1161-1162 (2006).

90 Anonymous. Respiratory depression from postoperative analgesia. Casebook 14 (3) (2006).

www.medicalprotection.org/uk/casebook/ september2006/case-reports/respiratorydepression-from-postoperative-analgesia

91 Conway BR, Fogarty DG, Nelson WE, Doherty CC. Opiate toxicity in patients with renal failure. Br. Med. J. 332, 345-346 (2006).

92 Ishiguro M, Hashimoto K, Hayakata Y, Fukunaga S, Seo N. Prolonged respiratory depression after fentanyl administration in a patient with mitochondrial encephalopathy (in Japanese). Masui 55, 73-75 (2006).

93 Lötsch J, Dudziak R, Freynhagen R, Marschner J, Geisslinger G. Fatal respiratory depression after multiple intravenous morphine injections. Clin. Pharmacokinet. 45, 1051-1060 (2006).

- Important case report showing that knowledge on both the pharmacokinetics and pharmacodynamics of the opioids we use is needed. Lack of such knowledge may lead to fatalities, as is illustrated in this case.

94 Nelson RY, Bretz B, Egan TD. Prolonged apnea after remifentanil. J. Clin. Anesth. 19, 60-63 (2007).

95 Robins K, Lyons G. Opioid-related narcosis in a woman with myopathy receiving magnesium. Int. J. Obstet. Anesth. 16, 367-369 (2007).
96 Rutili A, Maggiani M, Bertolloni C, Molinari D. Persistent overdose caused by a very small dose of intrathecal morphine in an elderly patient undergoing vaginal hysterectomy: a case report. Minerva Anestesiol. 73, 433-436 (2007).

97 Stamer UM, Stüber F, Muders T, Musshoff F. Respiratory depression with tramadol in a ptient with renal impairment and CYP2D6 gene duplication. Anesth. Analg. 107, 926-929 (2008).

98 Hill LR, Pichel AC. Respiratory depression after cadaveric renal transplant. Eur. J. Anaesthesiol. 26, 435-436 (2009).

99 Ouro-Bang'naMaman AF, Sama HD, Alassani F, Egbohou P, Chobli M. Late respiratory depression following intrathecal administration of morphine and clonidine in a 70 year old patient (in French). Ann. Fr. Anesth. Réanim. 28, 701-703 (2009).

100 Horng HC, Ho MT, Huang CH, Yeh CC, Cherng $\mathrm{CH}$. Negative pressure pulmonary edema following naloxone administration in a patient with fentanyl-induced respiratory depression. Anaesthesiol. Taiwan 48, 155-157 (2010).

101 Mbaye L, Graftieaux JP, Gomis P, Malinovsky JM. Can remifentanil be responsible for delayed respiratory depression? (in French). Ann. Fr. Anesth. Réanim. 29, 168-169 (2010).

102 Beebe D, Singh H, Jochman J, et al. Anesthetic complications including two cases of postoperative respiratory depression in living liver donor surgery. J. Anaesthesiol. Clin. Pharmacol. 27, 362-366 (2010).

103 Pandey R, Elakkumanan LB, Garg R, et al. Prolonged apnea after small single dose of tramadol. AANA J. 78, 110-111 (2010).

104 Tantry P, Kadam D, Shetty P, Adappa KK. Tramadol-induced respiratory depression in a morbidly obese patienty with normal renal function. Indian J. Anaesth. 55, 318-320 (2011).

105 Makris A, Matala NE, Tsirigotis A, Karmaniolou I. Apnea and mydriasis after postoperative tramadol administration: an unusual complication and possible underlying mechanisms. Anaesthesia 67, 76-77 (2012).

106 Nelson JA, Loredo JS, Acosta JA. The obesity-hypoventilation syndrome and respiratory failure in the acute trauma patient. J. Emerg. Med. 40, 67-69 (2011).

107 Bonner JC, McClymont W. Respiratory arrest in an obstetric patient using remifentanil patient-controlled analgesia. Anaesthesia 67, 538-540 (2012).

108 Pruefer C, Belway A. Respiratory arrest with remifentanil patient controlled analgesia - another case. Anaesthesia 67, 1044-1045 (2012).

109 Shaw KD, Amstutz U, Jimenez-Mendez R, Ross CJD, Carleton BC. Suspected opioid overdose case resolved by CYP2D6 genotyping. Drug Monit. 34, 121-123 (2012).

110 Marr R, Hyams J, Bythell V. Cardiac arrest in an obstetric patient using remifentanil patient-controlled analgesia. Anaesthesia 68, 283-287 (2013).

111 Dahan A, Niesters M, Smith T, Overdyk F. Opioids. In: Clinical Anesthesia (7th Edition). Barash P, Cullen BF, Stoelting RK (Eds). Lippincott Williams \& Wilkins.PA USA, 501-522 (2013).

112 Olofsen E, Boom M, Nieuwenhuijs D et al. Modeling the non-steady-state respiratory effects of remifentanil in awake and propofol sedated healthy volunteers. Anesthesiology 212, 1382-1395 (2010).

113 Sarton E. Olofsen E, Romberg R et al. Sex differences in morphine analgesia: an experimental study in healthy volunteers. Anesthesiology 93, 1245-1254 (2000).

114 Brown KA, Laferrière A, Lakheeram I, Moss IR. Recurrent hypoxemia in children is associated with increased analgesic sensitivity to opiates. Anesthesiology 105, 665-669 (2006).

115 Niesters M, Dahan A, Kest B et al. Do sex differences exist in opioid analgesia? A systematic review and meta-analysis of human experimental and clinical studies. Pain 151, 61-68 (2010).

116 Dahan A, Sarton E, Teppema L, Olievier CN. Sex-related differences in influence of morphine on ventilatory control in humans. Anesthesiology 88, 903-913 (1998).

117 Moss I, Brown KA, Laferrière A. Recurrent hypoxia in rats during development increases subsequent respiratory sensitivity to fentanyl. Anesthesiology 105, 715-718 (2006).

118 Lee LA, Domino KB. Factors associated with postoperative respiratory depression: from the ASA closed claims analysis. ASA Newsletter 77, 34-36 (2013).

119 Subramanyam R, Chidambram V, Ding L, Myer C, Sadhasivam S. Anesthesia- and opioid-related malpractice claims following tonsillectomy in USA: LexisNexis claims database 1984-2012. Ped. Anes. 24, 412-420 (2014).

120 Volkow ND, Frieden TR, Hyde PS, Cha SS. Medication-assisted therapies - Tackling the opioid-overdose epidemic. N. Eng. J. Med. 370 (22) 2063- 2066 (2014). 